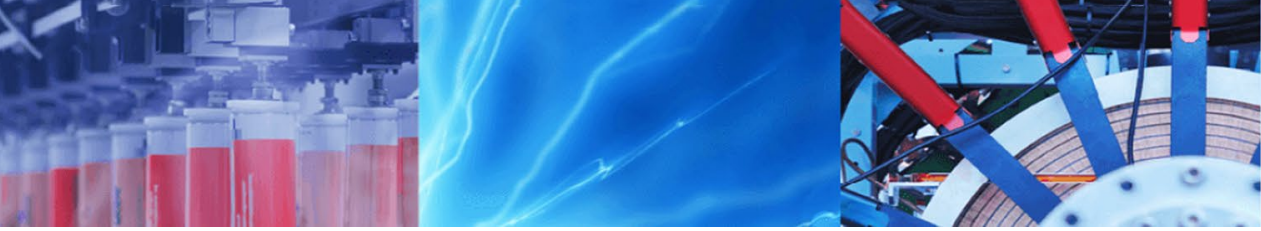

Research Article

\title{
A novel square wave generator based on the translinear circuit scheme of second generation current controlled current conveyor-CCCII
}

\author{
Umar Mohammad $^{1}$ D $\cdot$ Mohd Yusuf Yasin ${ }^{2} \cdot$ Romana Yousuf $^{1} \cdot$ Imtiyaz Anwar $^{1}$
}

(c) Springer Nature Switzerland AG 2019

\begin{abstract}
A robust square wave generator employing a sole capacitor and two resistors has been presented in this study. Low power as well as popular translinear circuit scheme of Second generation current controlled current conveyor-CCCII has been taken as an active element to implement the proposed square wave generator. CCCII inhibits promising features like availability of three mutually independently and electronically adjustable parameters corresponding transconductance $\left(g_{m}\right)$, intrinsic resistance $(r)$ of the current input terminal and current gain between two terminals) that are very prevalent for control applications accepted currently. The operating frequency of the proposed model has been analyzed with respect to the passive components present there, with no exposure of output signals to the thermal voltage $\left(\mathrm{V}_{T}\right)$. Electrical/Device properties (like Noise, Threshold, area etc.) of the proposed circuit have also been discussed in this work. The simulation work was carried out on Synopsis Hspice tool (v-2008.03) from Avant. Satisfying results with anticipation of theoretical and simulated results, including precision (consistency assessment) with Pareto analysis (Ist order Best Test flavored by Decision making analysis) were observed during the study. The $45 \mathrm{~nm}$ BSIM CMOS modelling parameters were adopted to prove the theory. The elementary purpose of using such parameters is to maximize the circuit drive and lowering the leakage current. Another purpose of using these modelling parameters is to enhance the realization of the proposed circuit in the form of chip die and further get it fabricated in custom Integrated circuit(IC) form, from a Standard local foundry. Maximum power consumption of the circuit is $600 \mu \mathrm{W}$, with $\pm 1 \mathrm{~V}$ rail to rail operating voltages.
\end{abstract}

Keywords Square wave generators · CCCII based novel MOS devices - Monte Carlo analysis · Voltage and current mode circuits $\cdot$ Low power and low voltage CMOS circuits

\section{Introduction}

In the recent years, the digitals systems have maintained strong dominance over the traditional analog systems due to their outstanding features and characteristics [1-6]. But still analog devices/circuits can't be overruled or neglected, for the reason of their long term consistency in various engineering fields, by the advantage of their promising features. Advancements in both the fields have framed and shaped the fourth industrial revolution. Likely, square wave generator is the basic building block of many signal processing elements like $A / D$ and $D / A$ converters, applied electronics and instrumentation [7-12]. In literature, a number of square wave generators have been presented, that differ among each other by one or the other feature. Multiple active devices have been utilized

This work was supported by the Special Assistance Program, SAP, at the Islamic University of Science \& Technology-IUST, Awantipora, Kashmir, India for the up gradation and improvement of the Institutional Technical education and research quality.

$\square$ Umar Mohammad, umarnaik@iul.ac.in; Mohd Yusuf Yasin, myyasin@iul.ac.in; Romana Yousuf, romana.yousuf@islamicuniversity.edu.in; Imtiyaz Anwar, imtiyaz.anwar@islamicuniversity.edu.in | ${ }^{1}$ Electronics Engineering Department, Islamic University of Science and Technology, Awantipora, Kashmir 192122, India. ${ }^{2}$ Department of Electronics and Communication Engineering, Integral University Lucknow, Lucknow 226026, India. 
to present the wave generator (C.L. Hou et al. used OTRA) [31], (Pal, D et al. used CCII) [19], (Silapan et al. used MOCCCDTA) [34], (Sotner, R et al. used ZC-CG-VDCC) [36]. In the paper, we are implementing the square wave generator using the translinear circuit scheme of CCCII. Dominant low power, low voltage devices with full availability of full bandwidth $(\lambda)$ are expected to ascend using CCCII schemes [13-20]. A detailed Analytical outlook of the pros and cons of the previous and present literature is also discussed in this paper. Fourier components of the voltage $(V)$ at the output node with signal components like frequency $(U)$, phase $(\Phi)$, normalized phase etc. through the reference of Total harmonic distortion (THD) and DC components have also been presented here. Active elements find applications in the field of signal generation, such as controllability of oscillation frequency, control of output amplitudes, duty cycle etc. [18-21].

\subsection{Literature review}

In literature, we came across different varieties of squarewave generator circuits based on multiple active elements. A detailed comparative summary has been kept in the Table 1 of this study. However, the basic overview of literature present relating the proposed circuit/waveform generators is below.

1. In [29], square wave generator employing two CCII and five passive elements has been reported. Circuit has been verified through simulation and practically using Spice level 1 transistor parameters and AD844AN IC respectively. Maximum range of the tunable frequency has been found $300 \mathrm{kHz}$. Power consumption of the circuit is $16.83 \mathrm{~mW}$.

2. C.L. Hou et al. in [32] [33] have presented square/ triangular wave generator with switch controllable OTRA's. The feasibility of these OTRA's have been verified using commercial AD844AN IC. This study has mainly focused on the practical demonstration of the waveform generators. Silapan et al. [34] have used MO-CCCDTA as an active device to enhance the realization of Schmitt triggers. Bipolar PNP and NPN Pspice transistor models were used to complete the verification purposes. A total of 27 transistors were used to complete the circuit. Moreover multiple devices like AD844AN and LM13600 N have been used to make the possible implementation of the proposed circuits. Enough simulation and calculations are reported in the study. Power consumption of one of the circuits is $235 \mu \mathrm{W}$.

3. In [35], Sotner, R et al. have presented ZC-CG-VDCC as an active element to implement the fully fledged functional generator using both current and voltage signals. Circuit topology of the active element was completed with $52 \mathrm{MOS}$ transistors using $0.18 \mu \mathrm{M}$ CMOS technology. Practical implementation of the design has also been reported using diamond transistors, buffer models-BUF634/OPA660/860 and two resistors. Backing this work, Sotner, $R$ et al. in [36], [37], [38] presented DT-VCA, DO-FB-VDBA \& CG-CDVA as active elements to (triangular/squarewave) waveform generators. Possible implementation in simulation and on practical hands have been done greatly. Frequent use of diamond transistor has been done by the authors. Theoretical fitting in these papers is presented greatly. In [39], [40] Srinivasulu, A et al. proposed waveform generators using CCII practically as well as through simulation. Reportedly Cadence Tools were used to simulate the circuit presented at [39] in CMOS micrometer technology, however, at [40] practical implementation of the proposed theory was illustrated using commercially available AD844AN IC's.

4. In [41], [46] Siripruchyanun, $M$ et al. proposed waveform generators using OTA and MO-VDTA. Pspice has been used to simulate the circuit presented in the above cited literature. [41] has reportedly enough application part exceeding square wave generation. BJT transistors has been used to prove the proposed theory. In [46], number of BJT transistors have been increased up to 36 and has been made essential for square/triangular waveform generation. Total Power consumption of the proposed circuit in the study is reported $14.3 \mathrm{~mW}$. In [42] Hung-Chun Chien proposed waveform generators DVCC. This paper presents a voltage-controlled dual slope operation square/triangular wave generator circuits. Various other applications based on multiple differential voltage current conveyors has been reported by the authors. Some practical simulations and verifications have also been proposed in the study. Overall power consumption of the circuit has been reported $763 \mathrm{~mW}$.

5. In [43], Vijay et al. have proposed squarewave generator using Second-Generation Differential Current Conveyor DCCII. Simulation of the circuit was done using cadence systems implying $180 \mathrm{~nm}$ gpdk parameters. In addition, hardware realization has also been reported using AD844AN. In $[45,47,48]$ chattervedi et al. have proposed multi output active devices MO-DXCCTA, MO-CIDITA for advanced square/triangular waveform generation. Reportedly in the particular literature, few hardware implementation have been done using the commercially available IC's AD844AN and LM13700. Satisfying cooperation of theoretical and practical outputs have been found. Probably, [48] is the only study that has proposed Schmitt trigger without any passive element. Various other features like high frequency, 
Table 1 Comparison of the state of art-square wave generator technologies

\begin{tabular}{|c|c|c|c|c|c|c|c|c|c|}
\hline Reference & $\begin{array}{l}\text { Active ele- } \\
\text { ment }\end{array}$ & $\begin{array}{l}\text { No of } \\
\text { active ele- } \\
\text { ments }\end{array}$ & $\begin{array}{l}\text { No of } \\
\text { passive } \\
\text { elements }\end{array}$ & $\begin{array}{l}\text { Grounded } \\
\text { capacitor } \\
\text { (s) }\end{array}$ & $\begin{array}{l}\text { Grounded } \\
\text { resistor (s) }\end{array}$ & $\begin{array}{l}\text { Hardware } \\
\text { imple- } \\
\text { mented }\end{array}$ & $\begin{array}{l}\text { Transistor type/IC } \\
\text { used }\end{array}$ & $\begin{array}{l}\text { Technol- } \\
\text { ogy node/ } \\
\text { Models }\end{array}$ & $\begin{array}{l}\mathrm{lb} / \\
\mathrm{Vcc}\end{array}$ \\
\hline $\begin{array}{l}\text { C.L. Hou } \\
\text { et al. [33] }\end{array}$ & OTRA & 1 & 4 & No & No & Yes & AD844AN & $\begin{array}{l}\text { Not appli- } \\
\text { cable }\end{array}$ & $\begin{array}{l}\text { N.A/ } \\
15 \mathrm{~V}\end{array}$ \\
\hline $\begin{array}{l}\text { C.L. Hou } \\
\text { et al. [32] }\end{array}$ & OTRA & 2 & 4 & No & No & Yes & AD844AN & $\begin{array}{l}\text { Not appli- } \\
\text { cable }\end{array}$ & $0.9 \mathrm{~mA} / 5 \mathrm{~V}$ \\
\hline $\begin{array}{l}\text { Pal D et al. } \\
\text { [29] }\end{array}$ & $\mathrm{CCll}$ & 2 & 5 & Yes & Yes & Yes & AD844AN & $\begin{array}{l}\text { Spice level } \\
1\end{array}$ & $5-10 \mathrm{~V}$ \\
\hline $\begin{array}{l}\text { Silapan } \\
\text { et al. [34] }\end{array}$ & $\begin{array}{l}\text { MO- } \\
\text { CCCDTA }\end{array}$ & 2 & 1 & Yes & No & Yes & BJT & $\mu \mathrm{M}$ & $1.5 \mathrm{~V}$ \\
\hline $\begin{array}{l}\text { Sotner R } \\
\text { et al. [35] }\end{array}$ & $\begin{array}{l}\text { ZC-CG- } \\
\text { VDCC }\end{array}$ & 1 & 4 & Yes & Yes & Yes & MOSFET & $0.18 \mu \mathrm{M}$ & $1 \mathrm{~V}$ \\
\hline $\begin{array}{l}\text { Sotner R } \\
\text { et al. [36] }\end{array}$ & DT-VCA & 3 & 2 & Yes & No & Yes & $\begin{array}{l}\text { VCA610, } \\
\text { OPA860/660 }\end{array}$ & - & $5 \mathrm{~V}$ \\
\hline $\begin{array}{l}\text { Sotner R } \\
\text { et al. [37] }\end{array}$ & $\begin{array}{r}\text { DO-FB- } \\
\text { VDBA }\end{array}$ & 2 & 3 & Yes & Yes & Yes & MOSFET & $0.18 \mu \mathrm{M}$ & $50 \mu \mathrm{A} / 1.2 \mathrm{~V}$ \\
\hline $\begin{array}{l}\text { Sotner R } \\
\text { et al. [38] }\end{array}$ & CG-CDVA & 1 & 2 & Yes & No & No & EL2082 & $\begin{array}{l}\text { Macro } \\
\text { models }\end{array}$ & $5 \mathrm{~V}$ \\
\hline $\begin{array}{l}\text { Srinivasulu } \\
\text { A et al. } \\
{[39]}\end{array}$ & $\mathrm{CCll}$ & 3 & 7 & Yes & Yes & Yes & MOSFET & $0.6 \mu \mathrm{M}$ & $6 \mathrm{~V}$ \\
\hline $\begin{array}{l}\text { Srinivasulu } \\
\text { A et al. } \\
{[40]}\end{array}$ & CCII & 3 & 7 & Yes & Yes & Yes & AD844AN & $\begin{array}{l}\text { Spice } \\
\text { model }\end{array}$ & $7 \mathrm{~V}$ \\
\hline $\begin{array}{l}\text { Siripruchya- } \\
\text { nun M } \\
\text { et al. [41] } \\
{[46]}\end{array}$ & $\begin{array}{l}\text { OTA, MO- } \\
\text { VDTA }\end{array}$ & $\begin{array}{l}3 \\
2\end{array}$ & $\begin{array}{l}3 \\
3\end{array}$ & $\begin{array}{l}\text { Yes } \\
\text { Yes }\end{array}$ & $\begin{array}{l}\text { Yes } \\
\text { Yes }\end{array}$ & $\begin{array}{l}\text { Yes } \\
\text { No }\end{array}$ & BJT & $\begin{array}{l}\text { Pspice } \\
\text { model/ } \\
\mu \mathrm{M}\end{array}$ & $5 \mathrm{~V}$ \\
\hline $\begin{array}{l}\text { Chien et al. } \\
\text { [42] }\end{array}$ & DVCC & 2 & 4 & Yes & Yes & Yes & AD844AN & $\begin{array}{l}\text { Spice } \\
\text { Model }\end{array}$ & - \\
\hline $\begin{array}{l}\text { Vijay et al. } \\
\text { [43] }\end{array}$ & DCCII & 1 & 3 & Yes & Yes & Yes & MOSFET & $180 \mathrm{~nm}$ & $2.5 \mathrm{~V}$ \\
\hline $\begin{array}{l}\text { Chattervedi } \\
\text { et al. [45, } \\
47-50]\end{array}$ & $\begin{array}{l}\text { DXCCTA/ } \\
\text { MO-CIDITA }\end{array}$ & 7 & 22 & Yes & Yes & Yes & AD844AN,LM13700 & $\begin{array}{l}\mu \mathrm{M} / \\
90 \mathrm{~nm}\end{array}$ & - \\
\hline $\begin{array}{l}\text { Ranjan } \\
\text { et al. [51] }\end{array}$ & FTFN & 1 & $2 / 3 / 8 / 10$ & Yes & Yes & Yes & AD844AN & $\mu \mathrm{M}$ & $1.65 \mathrm{~V}$ \\
\hline $\begin{array}{l}\text { PROPOSED } \\
\text { (Fig. 3) }\end{array}$ & CCCII & 1 & 2 & Yes & Yes & No & MOSFET & $45 \mathrm{~nm}$ & $8 \mu \mathrm{A} / 1 \mathrm{~V}$ \\
\hline
\end{tabular}

OTRA Operational trans resistance amplifier

MO-CCCDTA Multiple-output current controlled current differencing transconductance amplifier

ZC-CG-VDCC z-copy controlled-gain voltage differencing current conveyor

$D T$-VCA Dual transistor voltage controlled amplifier

$D O-F B-V D B A$ Dual output fully balanced-voltage differencing buffer amplifier

CG-CDVA controlled gain current and differential voltage amplifier

CCII Second generation current conveyor

OTA Operational transducer amplifier

DVCC Differential voltage current conveyor

DCCII Second generation differential current conveyor

DXCCTA Dual-X current conveyor transconductance amplifier

MO-VDTA Multi output voltage differencing transconductance amplifier

CCCII Second generation current controlled current conveyor 
controllable duty cycle have also been found in the above literature.

6. Ranjan et al. in [51] have presented FTFN based Schmitt trigger enlightening the behaviors of square and triangular waveform generation. Pulse width modulation scheme has been used to enhance the realization of the proposed circuitry. Micrometer technology in Pspice tool has been used for the realization of the circuit. Finally hardware implementation has been done using AD844IC. Power Consumption has been figured at $2.4 \mathrm{~mW}$ in the study.

While concluding the literature and revealing the post justification, excellence and the commensurate advantages of the proposed design, fewer thing can be settled down finally. Firstly an ultimate low power circuit, implemented using the translinear circuit scheme of second generation current conveyor-CCCII has been presented. Which according to the author's best knowledge isn't available yet in the literature present. Furthermore, proposed Circuit has lesser complexity in terms of design and component requirement. In standings with the comparative operating frequency, CCCII based squarewave generator is expected to work in megahertz range $(\mathrm{MHz})$. Higher slew rate in Gigahertz $(\mathrm{GHz})$ has been found, during the simulation study of the circuit. Finally, a good handoff of theoretical and practical results was seen in the study.

\section{Cccii Design, Non Idealities And Considerations}

The scheme, we have adopted in the second generation current conveyor is the current mirror based translinear circuit (CCCI +) [13] shown below in Fig. 1. The advantage of using this circuit scheme is that it is fully balanced. The intrinsic resistance in this type can be balanced by tuning the biasing current $\mathrm{I}_{\mathrm{b}}$.

The matrix representation of CCCII is below;

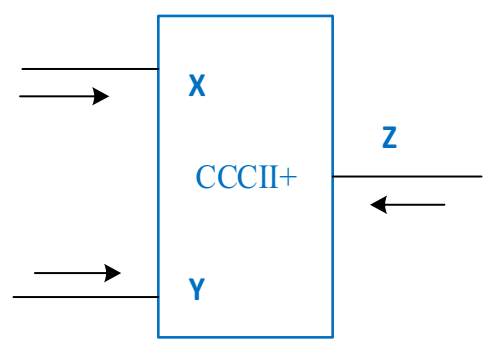

Fig. 1 General representation of CCCII+
From the above matrix as shown in Fig. 2, we can conclude the following things relating the operation of CCCII \pm .

$I_{y}=0$

$V_{x}=V_{y}+I_{x} \cdot R_{x}$

$I_{z+}=+I_{x}$

$I_{z-}=-I_{x}$

Resistance at $x=R_{x}=\frac{1}{2 g m}=\frac{1}{\sqrt{8 \beta_{n}}} I_{b}$

where $\beta_{n=} \mu_{n} C_{o x} \cdot \frac{W}{L}$

The above equations are well defined from the above matrix in Fig. 2 , in which we have, $I_{y}$ is the node current at Port $Y . V_{x}$ refers to voltage at node $X . V_{y}$ is the voltage at node $Y . I_{z}$ and $V_{z}$ are the current and Voltages at the node $Z$ respectively. Lastly, $R_{\mathrm{x}}$ is the intrinsic resistance of the translinear circuit. $R_{X}$ present at port $X$ depends inversely on bias current (IB). The parasitic resistance $\mathrm{RX}$ of terminal $\mathrm{X}$ is proportional to $1 / \mathrm{I}_{\mathrm{B}}$ for $\mathrm{BJT}$ realizations and inversely proportional to the square root of the bias current for CMOS realization [56] [57]. The Limitations of the CCII enhanced by Fabre resulted the new the new device termed as Current controlled current conveyorCCCII. Inclusion of Rx was shown in the particular device, in order to balance the adjustment of the voltage relationship between node $X$ and node $Y$, thereby imparting tunability to the device.

Some of the promising features of the CCCII are viz. [22-26]

1. Greater Linearity and Current mode Applicability.

2. Availability of full bandwidth.

3. Auto balancing at higher temperatures.

4. Low power \& low voltage.

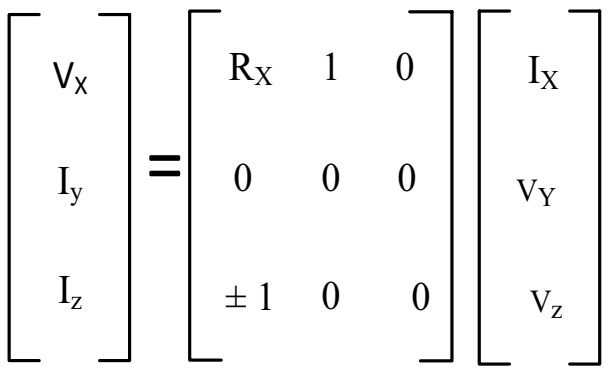

Fig. 2 Matrix representation of CCClI 


\section{Proposed and implemented square wave generator}

In literature a Variety of circuits quoting reference of square wave generator are available. Few circuits employing CCII $[39,40]$ as an active device are available. But no such circuit with the translinear circuit scheme of CCCII is available yet. CCCII is expected to enhance the features of the existing literature, because of its dominant features as described above. The literature available has been compiled in the table below.

Figure 3 shows the presented square wave generator circuit. One $\mathrm{CCCII}+$, one capacitor (C), and only two resistors $\left(R_{1}\right.$ and $\left.R_{2}\right)$ have been used to implement the circuit. Translinear circuit topology used to drive CCCII + has been put forth here for the readers.

Captivating $\mathrm{CCClI}+$ as an active principal component and casually joined passive components fashioned a novel square wave generator is shown in Fig. 4, with a single capacitor and two resistances. The Parasitic elements can be tuned to obtain the self-satisfying (commercially needed for loT and Coginitive radio) simulation results.

Considering the ideal input/output terminal characteristics of the CCCII+documented in Figs. 1, 2, 3 and 4 and Eqs. (1-5). Referring to the notations as shown in Fig. 3 and for ideal CCCII, $i_{y}=0: v_{x}=v_{y}+i_{x} \cdot r_{x}: i_{z}^{+}=+i_{x}: i_{z}^{-}=-i_{x}$ and $v_{x}=v_{y}$ therefore, $i_{x}$ flows out of the node $X$ as shown in Fig. 3.

A detailed analysis of the Time period can be investigated from the desired corresponding specimen wave form (provided in Fig. 5) of the proposed circuit.

From the Fig. 5, we have two possible saturation levels pointed as $\mathrm{L}+$ and $\mathrm{L}-$ for the output voltage $\mathrm{V}_{0}$. Individual Steady state operations can be made for the charging as well as the discharging mode of the capacitor. Alternate

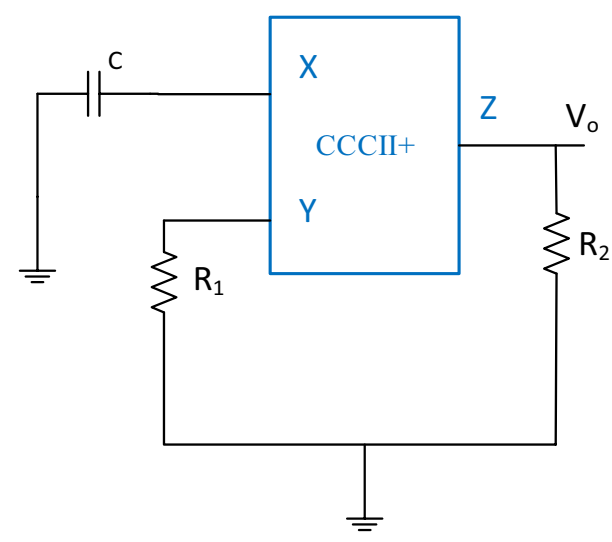

Fig. 3 Proposed circuit of square wave generator

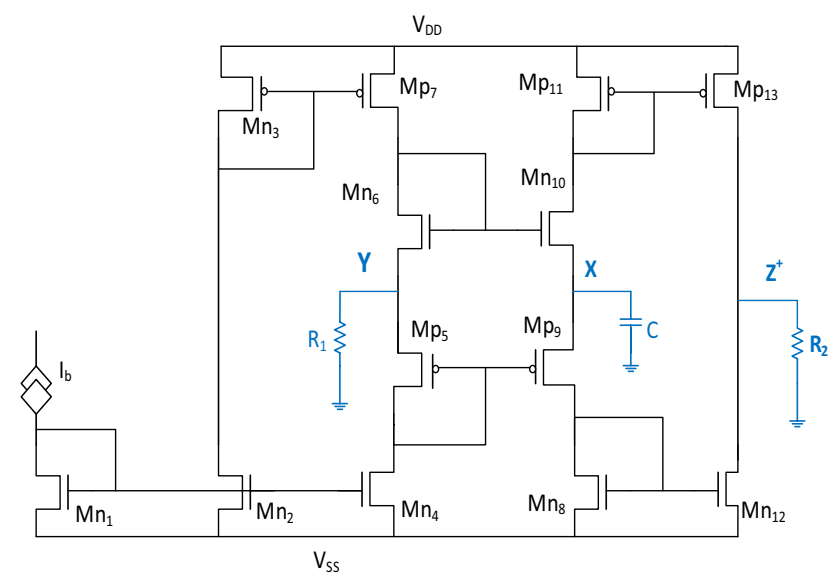

Fig. 4 Proposed circuit implemented using CMOS translinear circuit topology

standard equations presented in the literature [44], [43] can also be followed to sum up the circuit description. Theoretical calculations based on the commensurate observations from Fig. 5 leads us to reveal the probable equations for the time period.

$V_{\text {out }}=V_{x} \cdot R_{2} / R_{1}$

Now, the Standard charging equation for a Capacitor can be written as;

$q=C V\left(1-e^{-t / R C}\right)+q_{0} \cdot e^{-t / R C}$

Further, few conclusions can be made for the rising waveform viz: $\left(V_{c(t)}=\lambda \cdot V_{\text {out }} ; V_{T L}=-\lambda \cdot V_{D D} ; V_{T H}=V_{D D}\right)$

Hence Eq. 6, can be written as;

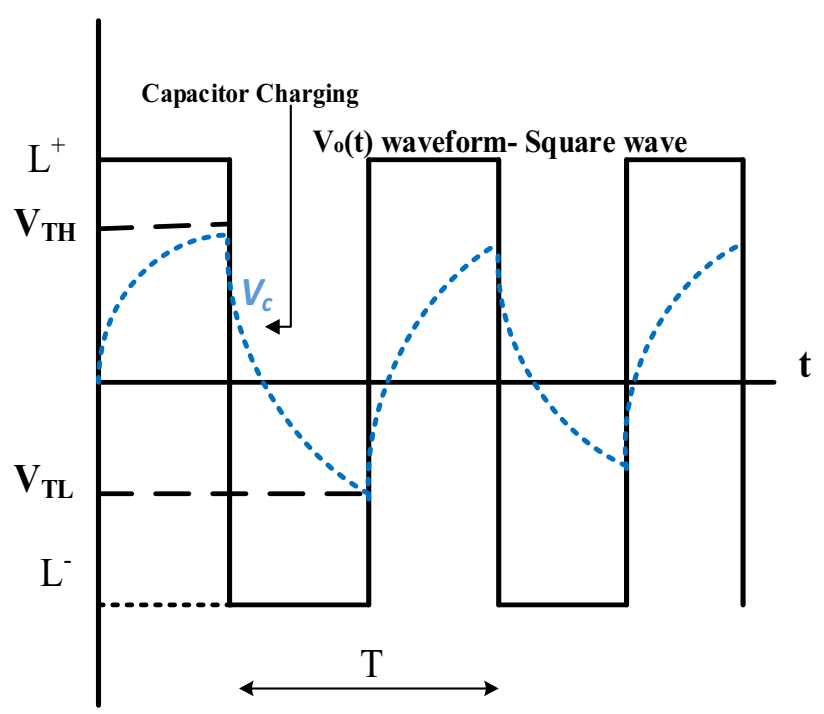

Fig. 5 Specimen waveform of the proposed design 
$q=C \cdot V_{D D}\left(1-e^{-t / R C}\right)-\lambda \cdot C \cdot V_{D D} \cdot e^{-t / R C}$

Now, Considering the Fig. 5, when the charging voltage switches from one cycle to another, a change occurs at the extreme points of $V_{T H}$ and $V_{T L}$ and surely the time $t=T / 2$ for the particular squarewave and this particular change can be mathematically drafted in the Eq. 7 viz.

$-\lambda \cdot C \cdot V_{D D}=C \cdot V_{D D}\left(1-e^{-T / 2 R C}\right)-\lambda \cdot C \cdot V_{D D} \cdot e^{-T / 2 R C}$

Solving above equation for Time period T, we have the following equation;

$\mathrm{T}=2 \mathrm{R}_{1} \operatorname{Cln} \frac{1+\lambda}{1-\lambda}$

Equation 8 represents the overall time period function of the circuit design to achieve behavior of square wave generator.

\section{Simulation results of the proposed square wave generator}

The results obtained from simulation study of the proposed circuit were quite adequate and satisfying in anticipation with the theoretical ones. Various types of analytical results were observed on the Cosmos Scope (C-Scope) tool provided by the Hspice tool from Avant. $45 \mathrm{~nm}$ bulk cmos modelling parameters [44] were used to simulate the implemented translinear circuit employing MOS transistors. Figure 6 is the output waveform of the circuit with overshoot $0.086 \%$ and undershoot of 0.0057348 (nearly $3.0277 \%$ ). Hence depict the exemplary linearity and

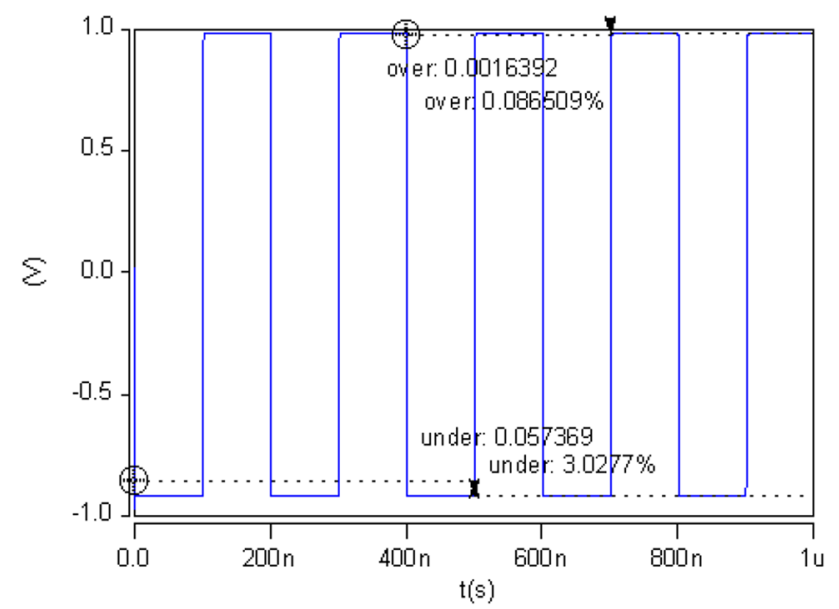

Fig. 6 Output waveform of the proposed square wave generator with the over and undershoot compressions consistency of the square waveform. A detailed analysis of the proposed circuit provided in the Fig. 4 was done, including the decision making analysis.

Figure 7 observed output electrical properties of the proposed circuit in Fig. 4: Rise time 666.97 ps and fall time 79.32 ps, Slew rate $2.1794 \mathrm{~g}$, Period of one cycle is $200 \mathrm{ns,}$ Frequency of $4.999 \mathrm{MHz}$, Duty cycle $0.49552 \mathrm{~s}$, Pulse width $99.105 \mathrm{~nm}$. Mean 0.14889, Median 0.52534, Range 1.9601 and Standard deviation 0.84512 (Table 2).

Figures 8 and 9 represent the histograms of the square wave generator in two forms. Former one pointed at Fig. 8 has number of bins $=20$, with the advantage of having impact with cumulative and normalising functions than the latter one shown in Fig. 9. Apart from this, Frequency Fourier transform analysis of the Fig. 4 is done here. FFT was done using the time increment linear/logarithmic, waveform view line/spectral, sampling frequency $-2.08 \mathrm{GHz}$ and window function using various scheme. Few parameters like total harmonic distortion-THD, signal to noise ratioSNR, Signal to noise and distortion ratio-SINAD were calculated for the proposed circuit. Phase and the Noise Plots of the circuit at the Fig. 4, have been analyzed using hann,

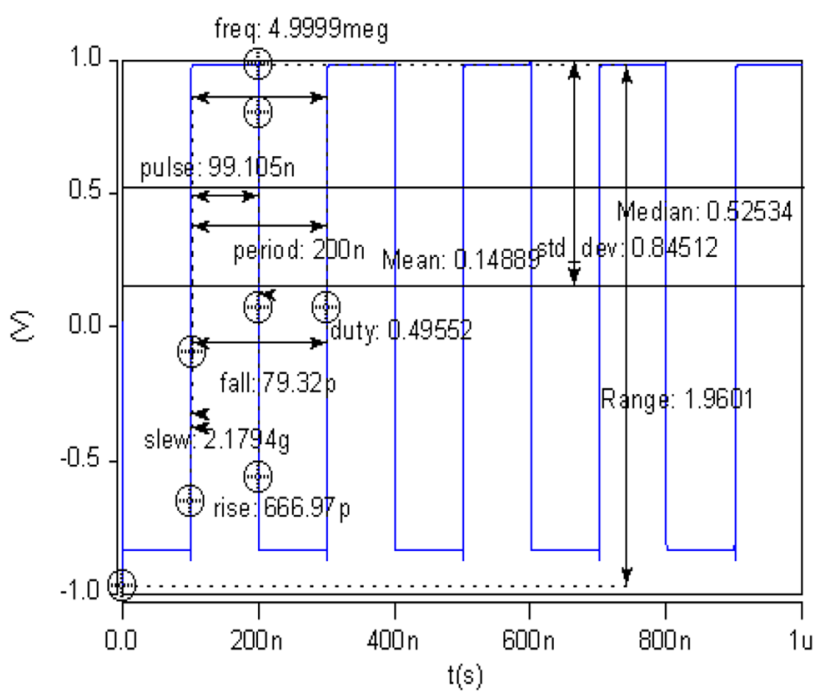

Fig. 7 Detailed analysis plot of the proposed circuit

Table 2 W/L of MOSFET'S used to implement proposed design

\begin{tabular}{lll}
\hline Transistor no. & Width (micrometer) & $\begin{array}{l}\text { Length } \\
\text { (microm- } \\
\text { eter) }\end{array}$ \\
\hline $\mathrm{Mn}_{1}, \mathrm{Mn}_{2}, \mathrm{Mp}_{5}, \mathrm{Mp}$ & $0.5 \mathrm{u}$ & $0.1 \mathrm{u}$ \\
$\mathrm{Mn}_{8}, \mathrm{Mn}_{10}, \mathrm{Mp} p_{13}$ & $0.5 \mathrm{u}$ & $0.1 \mathrm{u}$ \\
$\mathrm{Mp}_{3}, \mathrm{Mn}_{4}, \mathrm{Mn}_{6}, \mathrm{Mp}_{9}, \mathrm{Mp}_{11}, \mathrm{Mn}_{12}$ & $2.5 \mathrm{u}$ & $0.5 \mathrm{u}$ \\
\hline
\end{tabular}




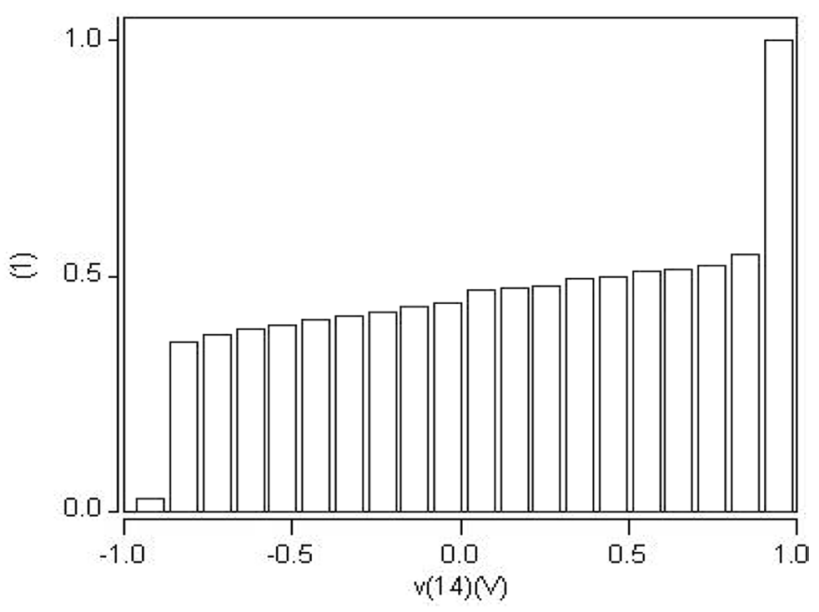

Fig. 8 Effective histogram of the proposed design

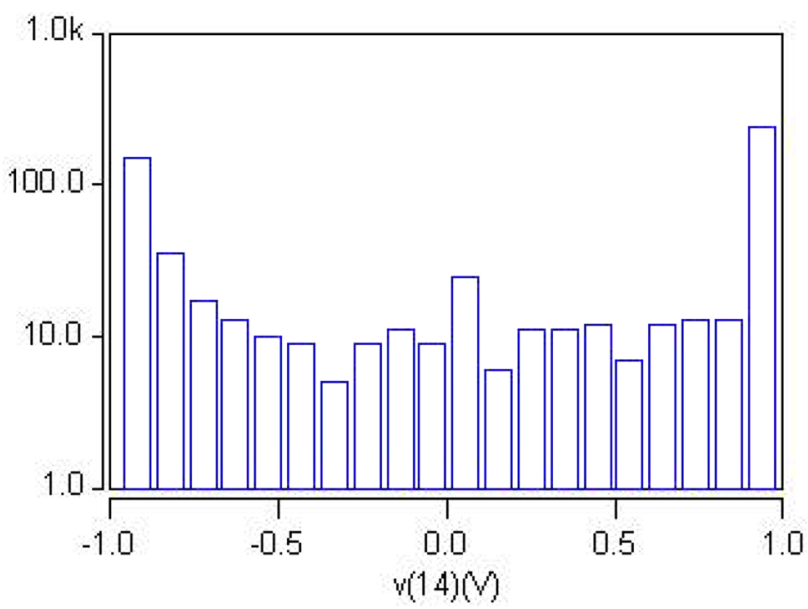

Fig. 9 Actual histogram of the proposed design

hamming, Blackman, flat top, cosine, rectangular and Bartlett window schemes. A quick overview of the results has also been summarized in the Table 3 below. For a total of 10 harmonics Fourier components at output (V(14)-O/P node) were observed with overall dc component finally figured at $9.39 \mathrm{E}-02$ and overall total harmonic distortion $43.2281 \%$.

In addition to the above analysis, several other circuit response have also used to analyse the behaviour of the proposed circuit. Continuity as well as the linearity of the design in Fig. 4 can be well deprived form these plots.

Detailed Ist order Best Fit Pareto Plot of the Proposed Circuit is signposted in the above plot involving the statistical measurement with comprehensive decision making analysis for the overall extreme performance of the various nodes as well the device/electrical properties for the expanded view (Translinear circuit Topology) of the proposed design presented in Fig. 4. In this Plot, X1 stands for the major active element $(\mathrm{CCCl}+), \mathrm{V}(13)$ is the voltage at the node $Y, V(12)$ represents voltage at node $X$ and $V(14)$ is the output voltage at node $Z$. TPOWER is the total power of the circuit, i(vss) and $i(v d d)$ are the drain and source currents. $x 1[v(5), v(3), v(4), v(8), v(7)$ and $\mathrm{v}(10)]$ are the voltages across the mos transistors as per the nomenclature adopted for the proposed circuit topology in the Fig. 5.

\section{Pre and post layout designs of the proposed circuit}

Layout simulations were carried out using Tanner tool (L-Edit-v16 and S-Edit-v16). A good agreement of satisfying results in both of the layouts and the performed spice simulations was seen. The width (W) and length (L) of the MOS were kept under the bounds of the Tanner Tool. Generic $250 \mathrm{~nm}$ device parameters were used for the prelayout simulation with $\mathrm{W}=1.5 \mathrm{u}$ and $\mathrm{L}=250 \mathrm{n}$. Further, a simplified post layout simulation has been put before the readers for better understanding, with MOS width of $450 \mathrm{~nm}$ and length of $250 \mathrm{~nm}$. Lastly, Simulations were observed out, using layout extraction method (Figs. 10, 11, 12, 13, 14, 15, 16, 17, 18, 19, 20, 21, 22 and 23).

Table 3 Comparative numerical analysis of THD, SNR and SINAD

\begin{tabular}{lccccrr}
\hline Parameter & Blackman response & Hamming response & $\begin{array}{l}\text { Rectangular } \\
\text { response }\end{array}$ & Flat top response & Cosine response & Bartlett response \\
\hline THD & 26.957 & 28.581 & 58.156 & 25.91 & 26.301 & 28.958 \\
SNR & -26.957 & -28.581 & -58.156 & 25.91 & -26.301 & -28.958 \\
SINAD & -26.957 & -28.581 & -58.156 & 25.91 & -26.301 & -28.958 \\
\hline
\end{tabular}

The detailed comparative summary of the Total harmonic distortion (THD), Signal to Noise ratio (SNR) and Signal to Noise and Distortion ratio (SINAD) is shown in the Table 3 Above 

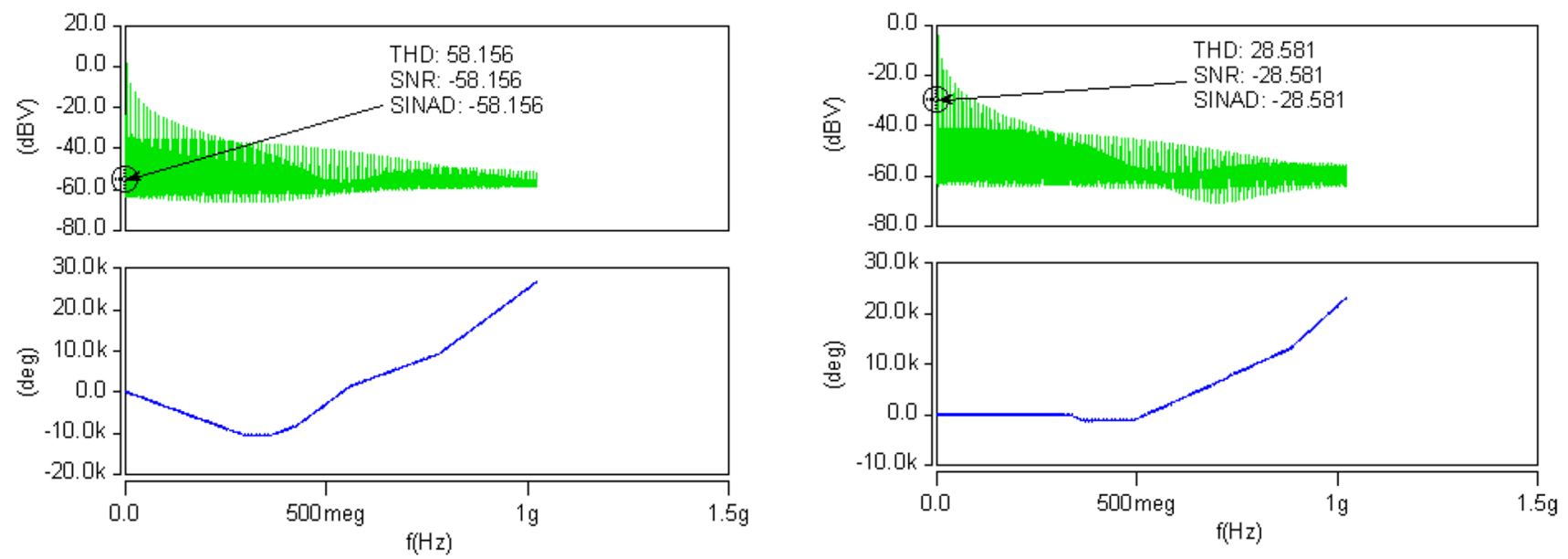

Fig. 10 FFT analysis using rectangular window scheme

Fig. 13 FFT analysis using Hamming window scheme
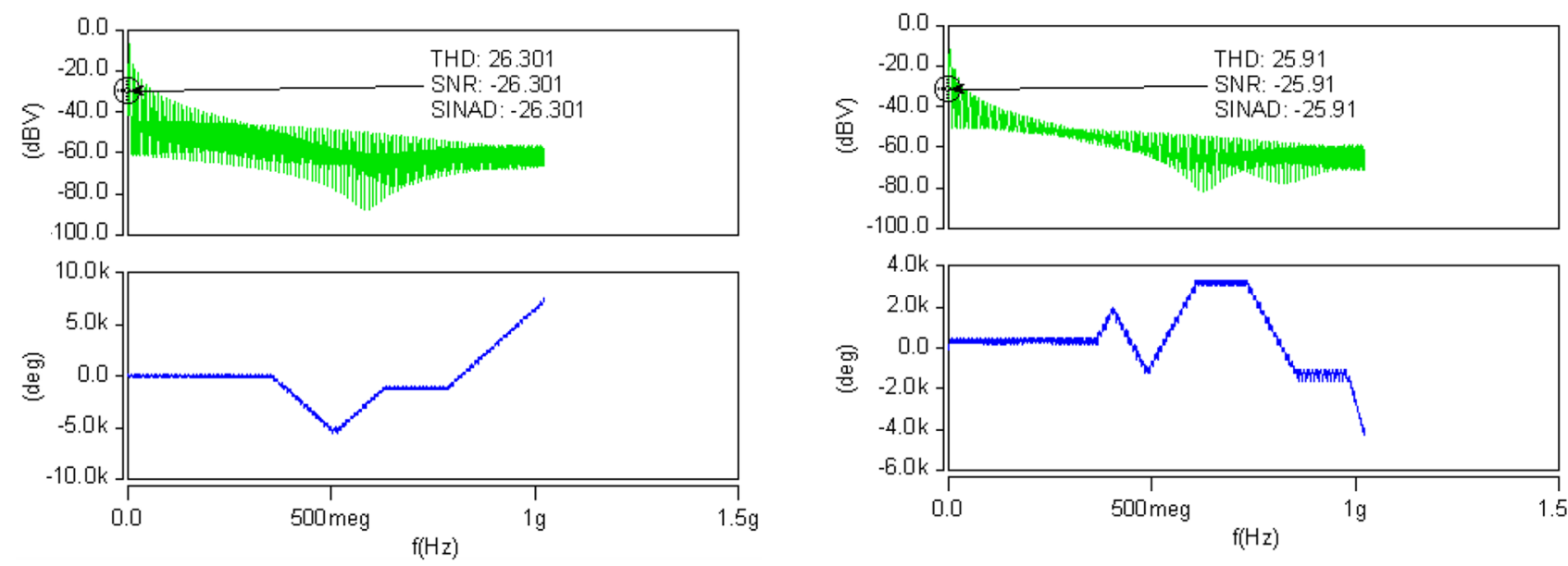

Fig. 11 FFT analysis using Blackman window scheme

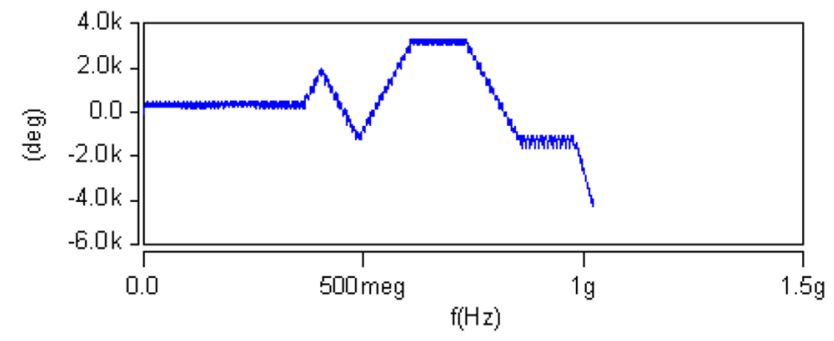

Fig. 14 FFT analysis using flatop window scheme
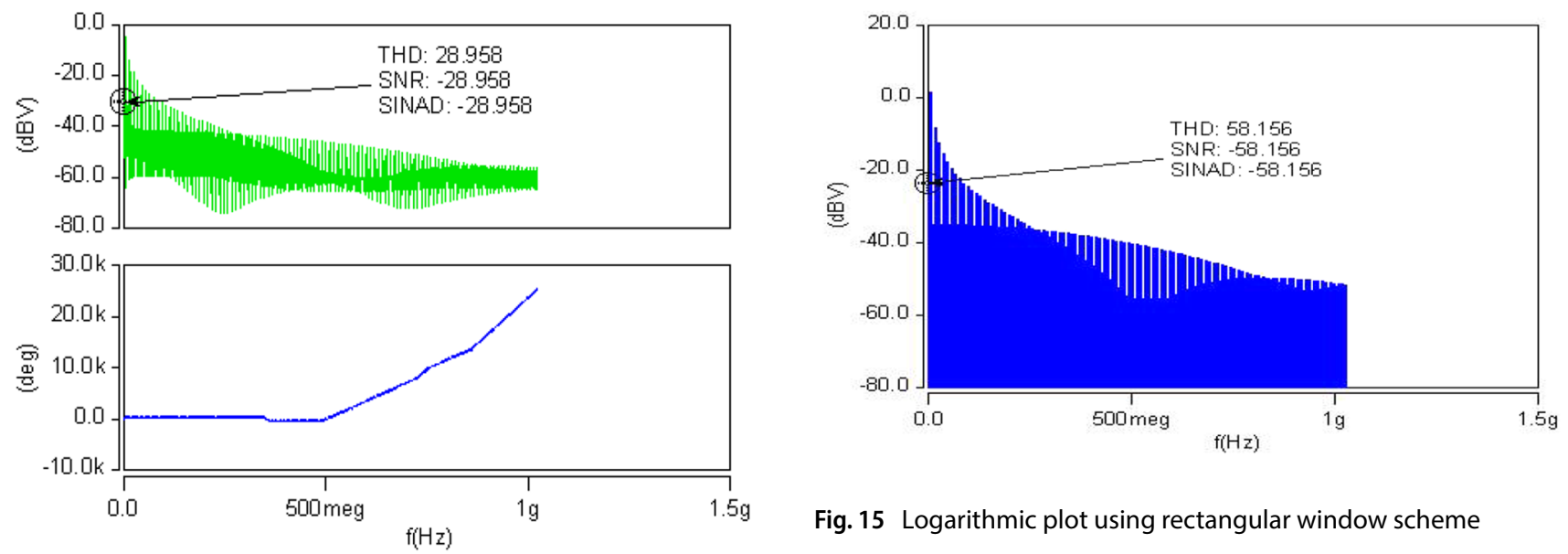

Fig. 15 Logarithmic plot using rectangular window scheme

Fig. 12 FFT analysis using Bartlett window scheme 


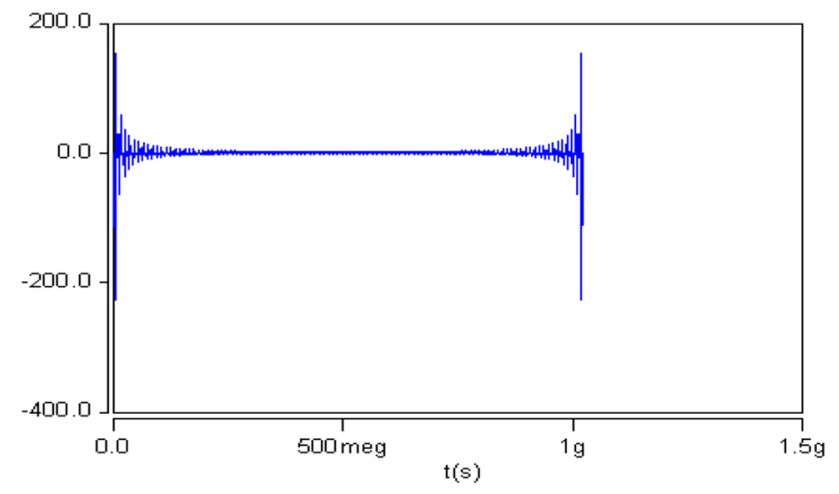

Fig. 16 IFFT plot of the proposed circuit

\section{Hardware implemention of the proposed circuit using conventional ad844 ic}

Commercially available CCII in the form of AD844 IC was used to realise the proposed square wave generator. Two $A D 844$ IC's were used as a single CCCII IC, for carrying out the realisation. Figure 24 shows the hardware schematic of the AD844 based square wave generator circuit.

Comparison of simulated and measured results The setup in the figure $X$ as well as the simulated results of the Fig. 4 , conclude the working of the circuits for wide range of frequencies up to the megahertz range $(\sim 4 \mathrm{MHz})$. However, a large variation of the supply voltage was seen in between the simulated and the measured circuits. AD844 based CCCII requires a supply voltage of not less than $5 \mathrm{~V}$, whereas the simulated circuit runs only on a supply voltage of $1 \mathrm{~V}$. Nevertheless, it is better to mention, that the layouts presented in the study have close comparison with the simulated results (Fig. 25).

\section{Evaluation of the pre and presented square wave generator circuits}

Circuits available in the literature possess the clarity as well as the conventional Industrial perspective too. In addition, the presented circuits in literature edify satisfying results,
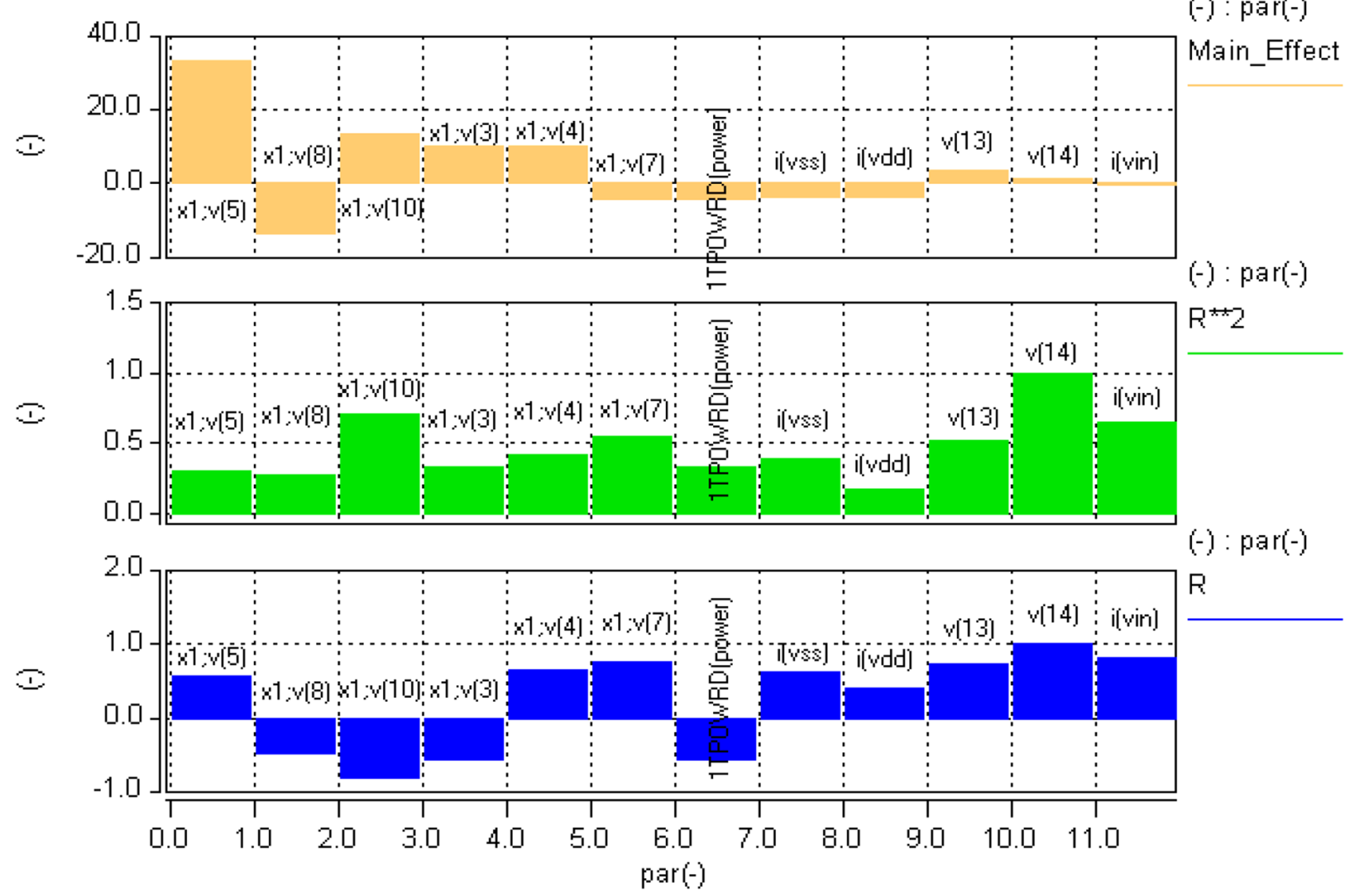

$(-)$ : par( () Main_Effect

$(-)$ : par(-) $\mathrm{R} \div 2$

Fig. 17 Pareto plot of proposed circuit 


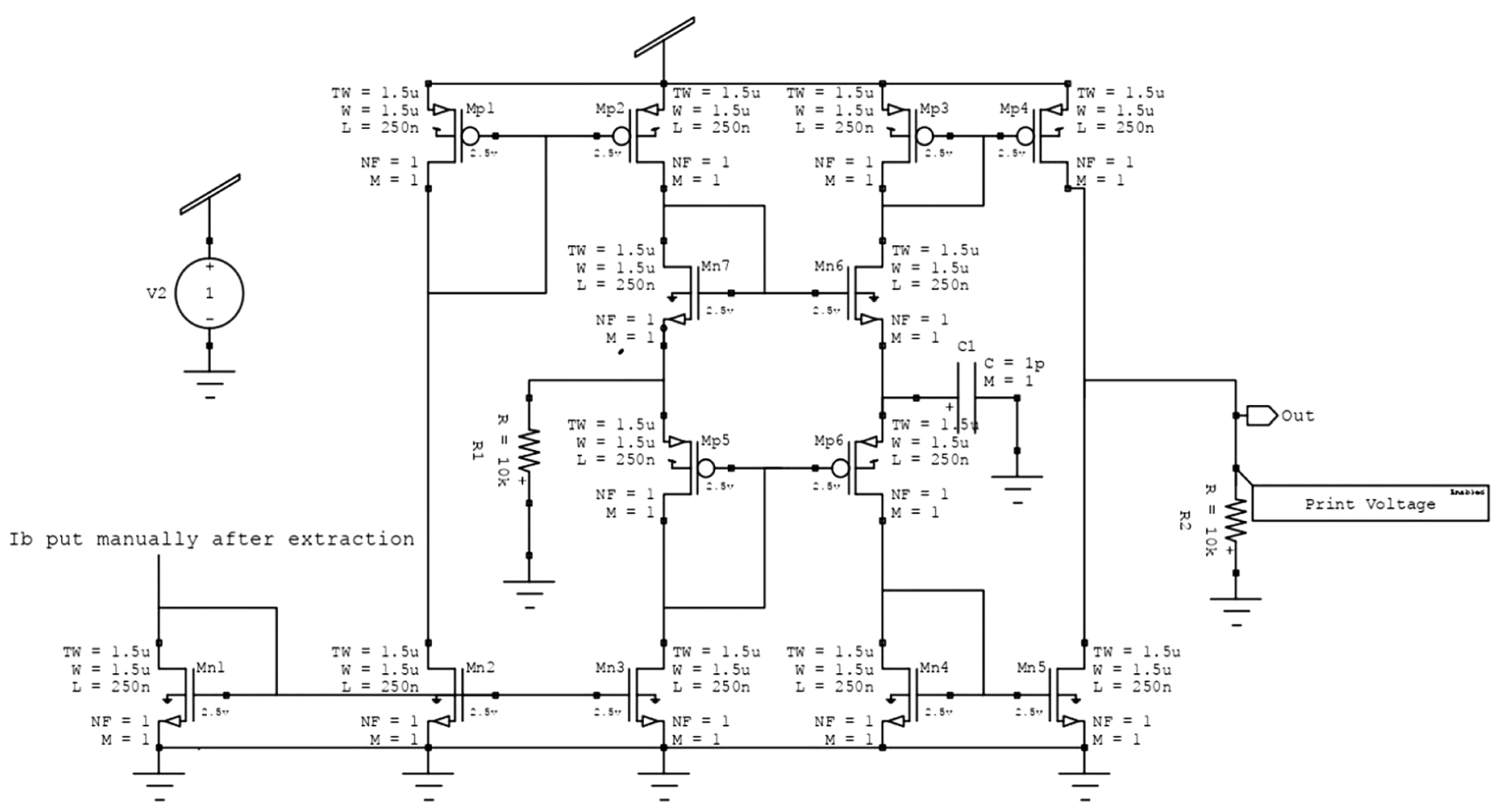

Fig. 18 Prelayout of the proposed circuit in S-Edit-v16 Mentor graphics Tool

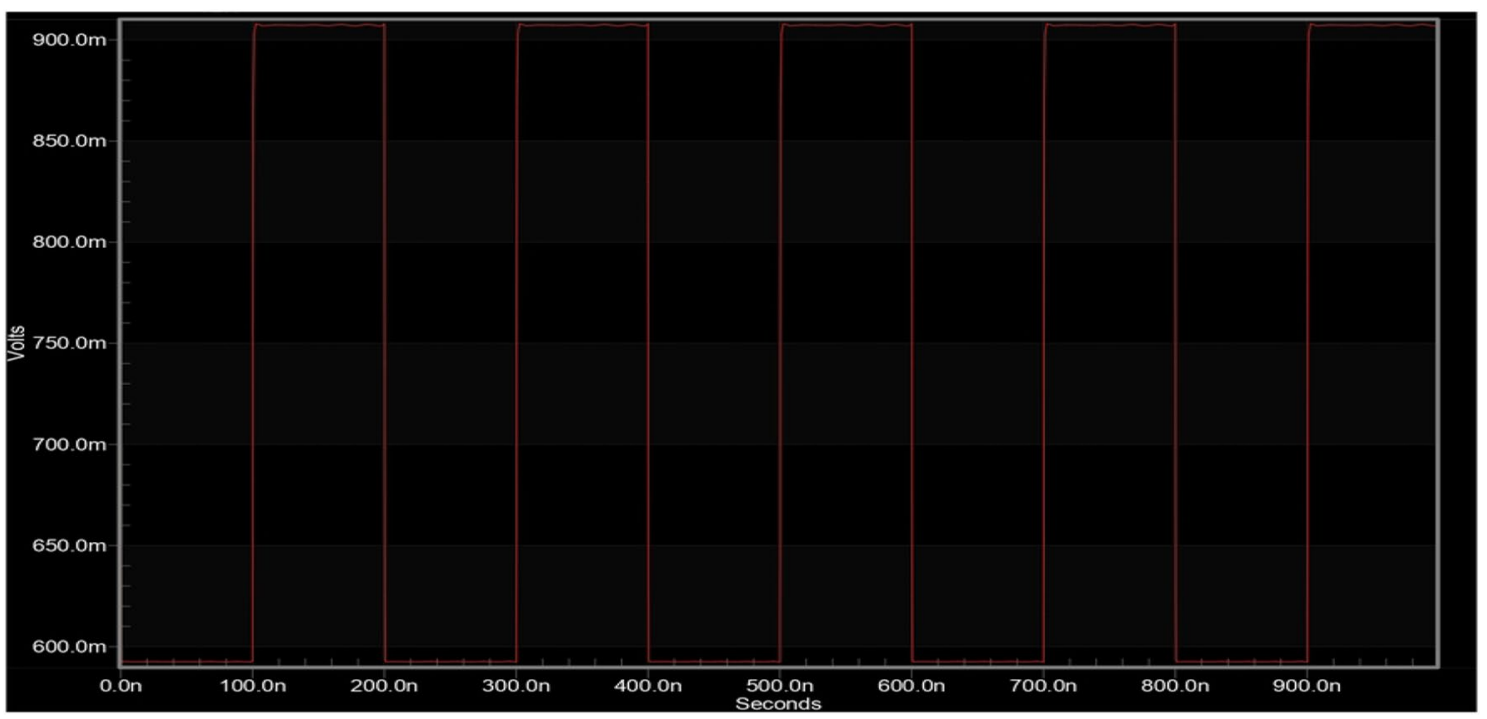

Fig. 19 Simulation O/P of the prelayout of the Fig. 18

however in the modern Industrial era of nanotechnology, an intense focus on chip Area and Power is kept whilst designing circuits. Circuits presented in the literature [13] [28] [29] have the drawback of having more number of active and passive elements than the presented in Fig. 4. Moreover, circuits presented at [16-22] [26] are lagging the grounding feature of passive elements. The striking feature of our work is the implementation of the square wave generator using the translinear circuit scheme of CCCII+ (with a single CCCII+as active device and all three passive elements grounded). To the author's prior knowledge, the presented circuit scheme is not available in the literature till now. Circuit designed in Fig. 5, facilitates low power, low voltage terminology, high slew rate, expected to give advanced performance at higher frequencies and first of its kind implemented in the ultra-deep submicron technology. Another thing that 


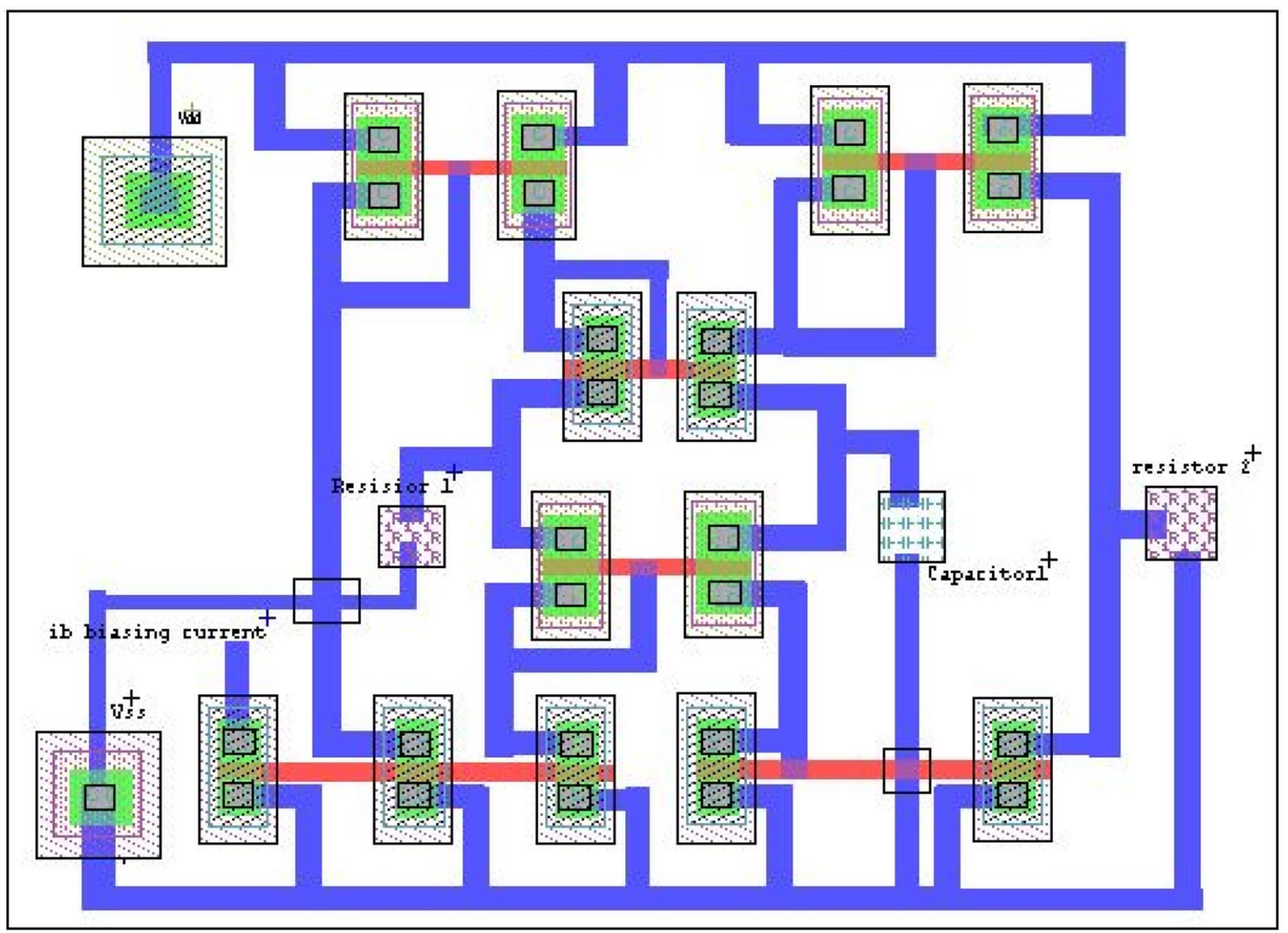

Fig. 20 Post layout of the proposed circuit in L-Edit-v16 Mentor graphics Tool

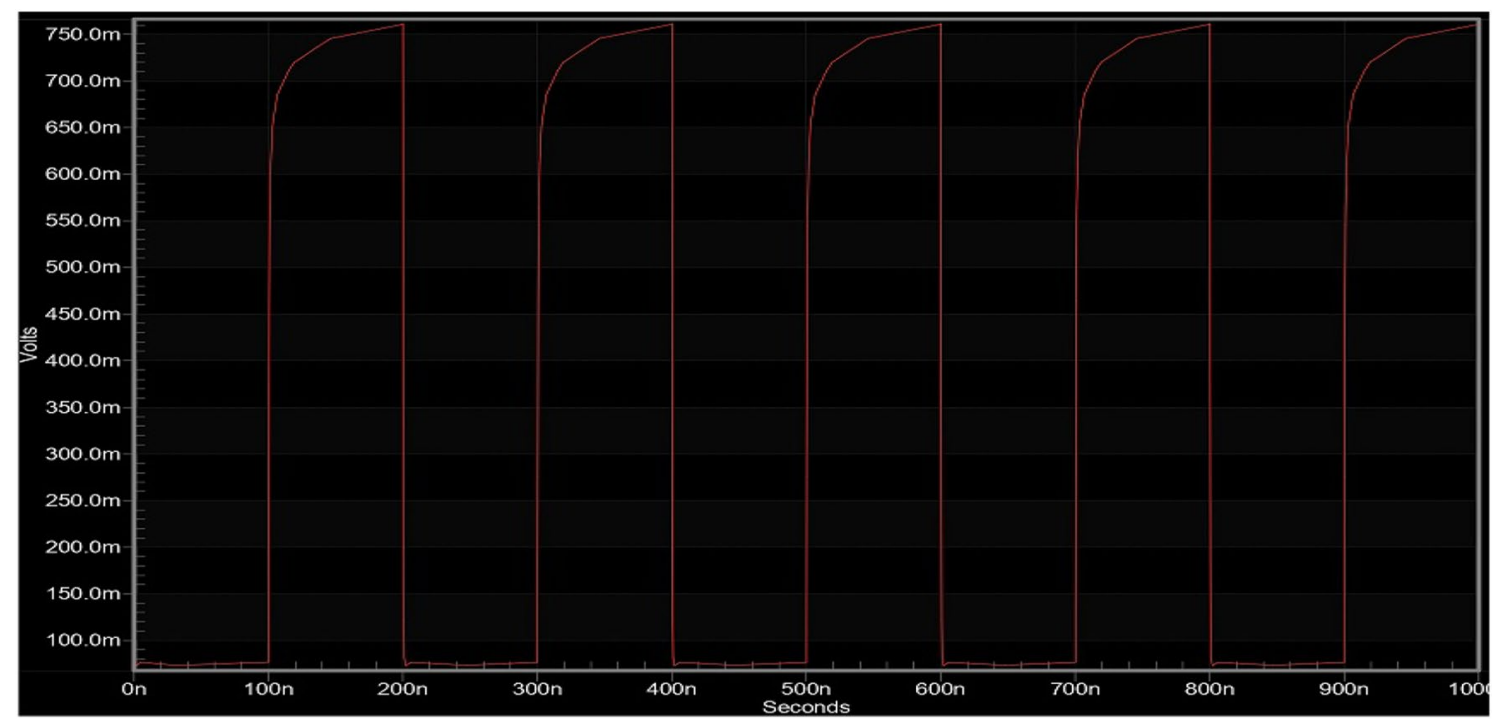

Fig. 21 Simulation O/P of the Post layout of the Figure $x$ 


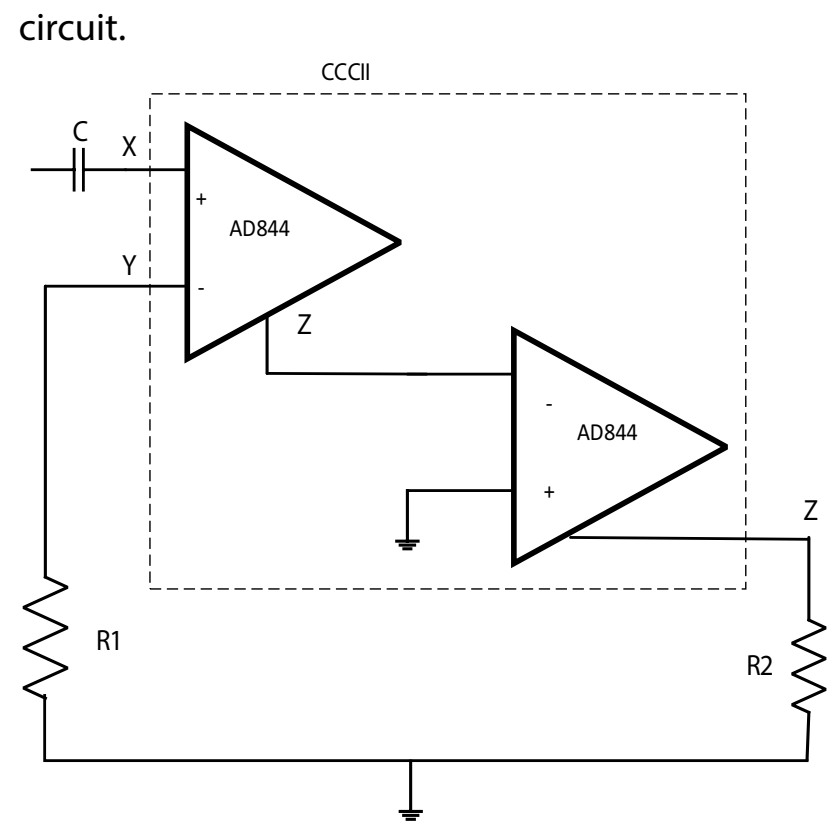

Fig. 22 Hardware setup of the proposed circuit

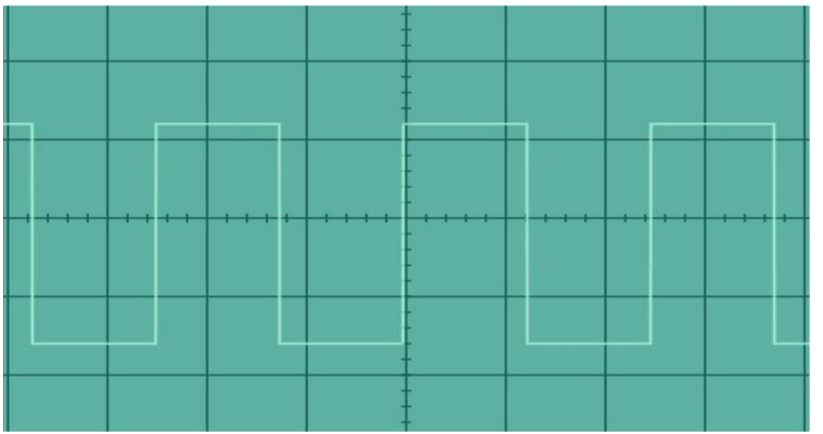

Fig. 23 Waveform (Seconds/Division: $1 \mathrm{~ms}$ and Volts/Division: $5 \mathrm{~V}$ ) on the oscilloscope of Figure $X$

differentiates this circuit scheme from the literature, is the use of Minimum number of MOS transistors occupied in the translinear circuit adopted. Total power consumption of the circuit is $600 \mu \mathrm{W}$, with $\pm 1 \mathrm{~V}$ rail to rail operating voltages. To the author's prior knowledge, the circuit (MOS based) presented guarantees the lowermost total power consumption amongst all the circuits presented in literature till date. However, only at [34], circuit presented using BJT's has extreme low power consumption. The reason behind the fact, that the total power consumption reported at [34] is less than the proposed circuit, is directly due to the implementation of the BJT's at the transistor level for Schmitt trigger device and not used as the switch or as active building blocks. Further, the application of the BJT and its dominance stem from the use in the particular application and utility. Graphical

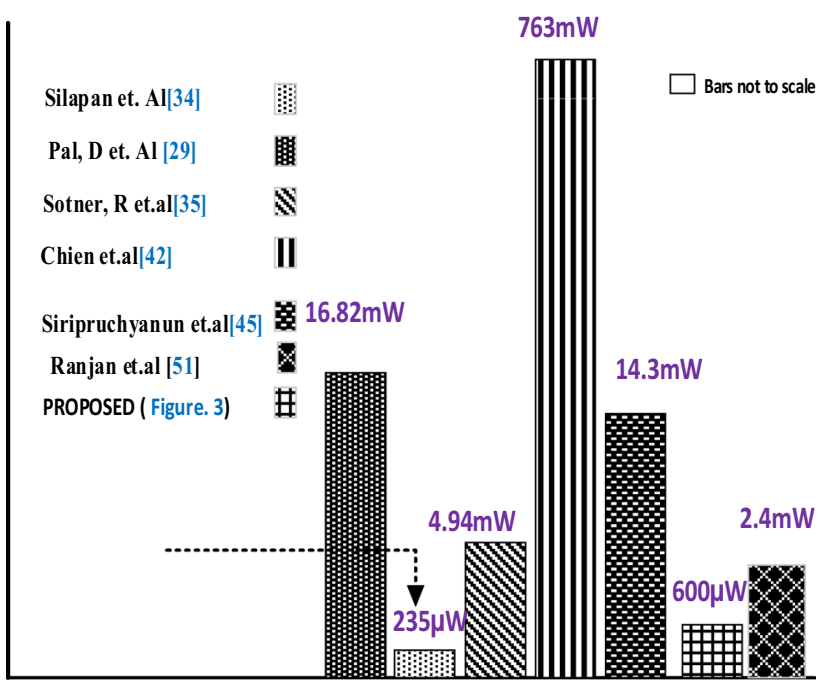

Fig. 24 Figure showing the comparative power consumption of the circuits presented in the literature and the proposed one in the Fig. 3 of this work

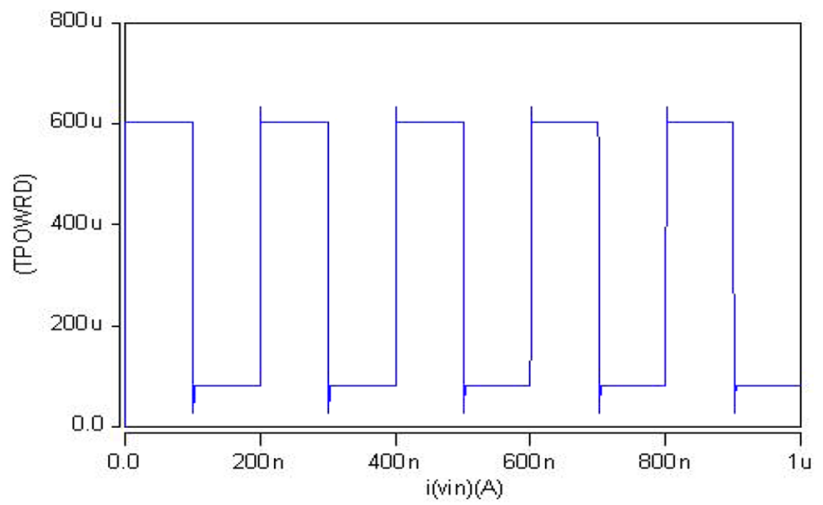

Fig. 25 Total Power Plot of the proposed squarewave circuit

plot of total power consumption of the circuits presented in the literature and the proposed one is shown below in the Fig. 18. To the Authors prior knowledge, the proposed circuit consumes the least power among all other circuits available in the literature. Main and possible reason behind the least power consumption is the implementation of the presented circuit using the $45 \mathrm{~nm}$ BSIM predictive modelling technology. Use of deep sub-micron parameters enhances greatly the higher drive as well as the minimization of the leakage current of the circuits.

\section{Conclusion and future work}

Low voltage and low power square wave generator using $\mathrm{CCCII}+$ is presented in this study. The circuit was implemented using a sole capacitor and two resistors. Simulated 
and Measured results of the circuit has been also detailed in the manuscript. Apart from the wide simulation analysis, the proposed circuit was also demonstrated practically using commercially available CCII, in the form of AD844 IC. A fair agreement and anticipation of theoretical and practical results was observed. Proposed circuit was passed through high level Pareto analysis with the scope of decision making. Satisfying results were obtained during the whole of the simulation processes. Presented circuit is expected to deliver sophisticated performance than the already existing in the literature. Total power consumption of the circuit is $600 \mu \mathrm{W}$, with $\pm 1 \mathrm{~V}$ rail to rail operating voltages. High frequency application part in the wider areas of electronics and communication are expected to be covered by the presented design. In Future, authors are making efforts to present the extended and enhanced simulations of the pre and post layouts using $45 \mathrm{~nm}$ technology parameters with the inclusion of DIE of the proposed circuit from the author's university lab. Finally, a compact and a minatursiated device fabricated from a local foundry is also expected to be put before the readers.

Acknowledgements The authors are thankful to the reviewers for their valuable comments.

\section{Compliance with ethical standards}

Conflict of interest The author(s) declare that they have no competing interests.

\section{References}

1. Smith KC, Sedra A (1968) The current conveyor-A new circuit building block. Proc IEEE 56(8):1368-1369

2. Fabre $A$ et al (1996) High frequency applications based on a new current controlled conveyor. IEEE Trans Circuits Syst I Fundam Theory Appl 43(2):82-91

3. Smith K, Sedra A (1970) Realization of the Chua family of new nonlinear network elements using the current conveyor. IEEE Trans Circuit Theory 17(1):137-139

4. Sedra AS, Smith KC (1970) A second-generation current conveyor and its applications. IEEE Trans Circuit Theory 17(1):132-134

5. Fabre A et al (1996) High frequency applications based on a new current controlled conveyor. IEEE Trans Circuits Syst I Fundam Theory Appl 43(2):82-91

6. Armağan $\mathrm{E}$, Kuntman $\mathrm{H}$ (2013) Configurable frequency agile filter application of balanced differential pair based CCCII circuit in $28 \mathrm{~nm}$ process. 2013 IEEE fourth Latin American symposium on circuits and systems (LASCAS). IEEE

7. Biolek D et al (2008) Active elements for analog signal processing: classification, review, and new proposals. Radioengineering 17(4):15-32

8. Yucek T, Arslan H (2009) A survey of spectrum sensing algorithms for cognitive radio applications. IEEE Commun Surv Tutorials 11(1):116-130

9. Stern E et al (2007) Label-free immunodetection with CMOScompatible semiconducting nanowires. Nature 445(7127):519
10. Berner B, Dunn TC, Farinas KC, Garrison MD, Kurnik RT, Lesho MJ, Potts RO, Tamada JA, Tierney MJ, Cygnus Inc, (2003). Device for signal processing for measurement of physiological analytes. U.S. Patent 6,595,919

11. Biolek D (2003) CDTA-building block for current-mode analog signal processing. Proc ECCTD 3:397-400

12. Fabre A et al (1996) High frequency applications based on a new current controlled conveyor. IEEE Trans Circuits Syst I Fundam Theory Appl 43(2):82-91

13. Awad IA (1999) Inverting second generation current conveyors: the missing building blocks, CMOS realizations and applications. Int J Electron 86(4):413-432

14. Fabre A, Saaid O, Barthelemy H (1995) On the frequency limitations of the circuits based on second generation current conveyors. Analog Integr Circuits Signal Process 7(2):113-129

15. Fabre A, Barthelemy H (1994) Composite second-generation current conveyor with reduced parasitic resistance. Electron Lett 30(5):377-378

16. Alzaher HA, Elwan H, Ismail M (2003) A CMOS fully balanced second-generation current conveyor. IEEE Trans Circuits Syst II Analog Digital Signal Process 50(6):278-287

17. Abbas Z, Scotti G, Olivieri M (2011) Current controlled current conveyor (CCCII) and application using $65 \mathrm{~nm}$ CMOS technology. World Acad Sci Eng Technol 55:935-939

18. Yasin MY, Gopal B (2011) High frequency oscillator design using a single $45 \mathrm{~nm}$ CMOS current controlled current conveyor $(\mathrm{CCClI}+)$ with minimum passive components. Circuits Syst 2(02):53

19. Biolek D et al (2008) Active elements for analog signal processing: classification, review, and new proposals. Radioengineering 17(4):15-32

20. Gray PR et al. (2001) Analysis and design of analog integrated circuits. Wiley

21. Chaisricharoen R, Chipipop B, Sirinaovakul B (2010) CMOS CCCII: structures, characteristics, and considerations. AEU-Int J Electron Commun 64(6):540-557

22. Wang C, Liu H, Zhao Y (2008) A new current-mode currentcontrolled universal filter based on CCCII $( \pm)$. Circuits Syst Signal Process 27(5):673-682

23. Chaisricharoen R, Chipipop B, Sirinaovakul B (2010) CMOS CCCII: structures, characteristics, and considerations. AEU-Int J Electron Commun 64(6):540-557

24. Ercan H, Alçı M (2013) A new design for a BiCMOS controlled current conveyor, Elektronika Ir Elektrotechnika 19(1): 56-60

25. Al-Shahrani SM, Al-Gahtani MA (2006) A new polyphase current-mode filter using digitally-programmable CCCII. In: 2006 international conference on microelectronics ICM'06, IEEE

26. Yasin MY (2013) A Novel bipolar XOR/XNOR realization using translinear type 2nd generation current controlled current conveyor designed in $45 \mathrm{~nm}$ CMOS technology. Acta Electrotehnica 54:3-6

27. Hou Chun-Li, Shen B (1995) Second-generation current conveyor-based multiphase sinusoidal oscillators. Int J Electron 78(2):317-325

28. Hou CL, Chien H-C, Lo Y-K (2005) Squarewave generators employing OTRAs. IEE Proc Circuits Devices Syst 152(6):718-722

29. Pal D, Srinivasulu A, Goswami M (2009) Novel current-mode waveform generator with independent frequency and amplitude control. In: Proceedings of the IEEE international symposium on circuits and systems-2009, Taipei, Taiwan, 24-27, pp. 2946-2949

30. Silapan P, Siripruchyanun M (2011) Fully and electronically controllable current-mode Schmitt triggers employing only single MO-CCCDTA and their applications. Analog Integr Circuits Signal Process 68(1):111-128 
31. Ercan H, Tekin SA, Alçı M (2015) Low-voltage low-power multifunction current-controlled conveyor. Int J Electron 102(3): 444-461

32. Lo Y-K, Chien H-C (2007) Switch-controllable OTRA-based square/triangular waveform generator. IEEE Trans Circuits Syst II Express Briefs 54(12):1110-1114

33. Hou CL, Chien H-C, Lo Y-K (2005) Squarewave generators employing OTRAs. IEE Proc Circuits Devices Syst 152(6):718-722

34. Silapan P, Siripruchyanun M (2011) Fully and electronically controllable current-mode Schmitt triggers employing only single MO-CCCDTA and their applications. Analog Integr Circuits Signal Process 68(1):111-128

35. Sotner R, Jerabek J, Herencsar N, Dostal T, Vrba K (2015) Design of Z-copy controlled-gain voltage differencing current conveyor based adjustable functional generator. Microelectron $J$ 46(2):143-152

36. Sotner R, Jerabek J, Herencsar N, Lahiri A, Petrzela J, Vrba K (2013) Practical aspects of operation of simple triangular and square wave generator employing diamond transistor and controllable amplifiers. In: Proceedings of the 36th international conference on telecommunications and signal processing (TSP 2013), Rome, Italy, 2-4, pp. 431-435

37. Sotner R, Jerabek J, Herencsar N (2013) Voltage differencing buffered/inverted amplifiers and their applications for signal generation. Radioengineering 22(2):490-504

38. Sotner R, Jerabek J, Herencsar N, Prokop R, Vrba K, Petrzela J, Dostal T (2013) Simply adjustable triangular and square wave generator employing controlled gain current and differential voltage amplifier. In: Proceedings of the 23th international conference radioelektronika, Pardubice, Czech Republic, 16-17, pp. 109-114

39. Srinivasulu A (2011) A novel current conveyor based Schmitt trigger and its application as a relaxation oscillator. Int J Circuit Theory Appl 39(6):679-686

40. Srinivasulu A (2009) Current conveyor-based square-wave generator with tunable grounded resistor/capacitor. In: Proceedings of the IEEE applied electronics international conference (AEIC 2009), Pilsen, Czech Republic, pp 233-236

41. Siripruchyanun $M$, Wardkein $P$ (2003) Afully independently adjustable integrable simple current controlled oscillator and derivative PWM signal generator. IEICE Trans Fundam Electron Commun Comput Sci 86(E12-A):3119-3126

42. Chien H-C (2012) Voltage-controlled dual slope operation square/triangular wave generator and its application as a dual mode operation pulse width modulator employing differential voltage current conveyors. Microelectron J 43(12):962-974

43. Vijay V, Srinivasulu A (2017) A novel square wave generator using second-generation differential current conveyor. Arab J Sci Eng 42(12):4983-4990

44. Simpson RE (1974) Introductory electronics for scientists and engineers. Allyn and Bacon, Boston

45. Chaturvedi B, Kumar A (2018) A novel electronically controlled Schmitt trigger with clockwise and anticlockwise hystereses. AEU Int J Electron Commun 89:136-145

46. Siripruchyanun $M$ et al (2016) A Current-mode square/triangular ware generator based on multiple-output VDTAs. Procedia Comput Sci 86:152-155
47. Chaturvedi B, Kumar A (2018) A novel linear square/triangular wave generator with tunable duty cycle. AEU Int J Electron Commun 84:206-209

48. Kumar A, Chaturvedi B (2017) Novel electronically controlled current-mode Schmitt trigger based on single active element. AEU Int J Electron Commun 82:160-166

49. Chaturvedi B, Kumar A (2018) Fully electronically tunable and easily cascadable square/triangular wave generator with duty cycle adjustment. J Circuits Syst Comput. https://doi. org/10.1142/S0218126619501056

50. Kumar A, Chaturvedi B, Maheshwari S (2017) A fully electronically controllable Schmitt trigger and duty cycle modulated waveform generator. Int J Circuit Theory Appl 45(12):2157-2180

51. Ranjan A, Pamu H, Tarunkumar H (2018) A novel Schmitt trigger and its application using a single four terminal floating nullor (FTFN). Analog Integr Circuits Signal Process 96(3):455-467

52. De Marcellis A, Di Carlo C, Ferri G, Stornelli V (2013) A CCII-based wide frequency range square waveform generator. Int J Circuit Theory Appl, ISSN, pp 0098-9886

53. De Marcellis A et al (2009) A novel low-voltage low-power fully differential voltage and current gained CCII for floating impedance simulations. Microelectron J 40(1):20-25

54. Stornelli V, Ferri G (2014) A single current conveyor-based low voltage low power bootstrap circuit for electrocardiography and electroencephalography acquisition systems. Analog Integr Circuits Signal Process 79:171-175. https://doi.org/10.1007/s1047 0-013-0252-2

55. Amlik S et al. (2015) A CCII-based wide frequency range square/ triangular wave generator. In: 2015 IEEE 2nd international conference on recent trends in information systems (retis), Date of Conference: 9-11 July 2. https://doi.org/10.1109/retis .2015 .7232920

56. Ercan H, Alci M (2013) A new design for a BiCMOS controlled current conveyor. Elektronika ir Elektrotechnika 19(1):56-61

57. Fabre A, Saaid O, Wiest F, Bouchron C (1995) Current controlled bandpass filter based on translinear conveyors. Electron Lett 31(20):1727-1728

58. Chaisricharoen R, Chipipop B, Sirinaovakul B (2010) CMOS CCCII: structures, characteristics, and considerations. Int J Electron Commun 64:540-557

59. Yuce E (2008) Design of a simple current-mode multiplier topology using a single CCCII+. IEEE Trans Instr Meas 57(3):631-637. https://doi.org/10.1109/TIM.2007.910112

60. Zahiruddin S, Srinivasulu A (2015) A high frequency tunable sinusoidal oscillator using single CCCII +. In: Proceedings of IEEE international conference on control, instrumentation, communication \& computational technologies, Kumaracoil, India, 18th and 19th December, pp 462-465. https://doi.org/10.1109/iccic ct.2015.7475323

61. http://ptm.asu.edu

Publisher's Note Springer Nature remains neutral with regard to jurisdictional claims in published maps and institutional affiliations. 